\title{
Agronomic Performance of Collards under Two Intercrops and Varying Nitrogen Application Levels as Assessed Using Land Equivalent Ratios
}

\author{
Samuel Kilonzo Mutiga (Corresponding author) \\ Department of Plant Pathology and Plant-Microbe Biology, Cornell University \\ 334 Plant Science Building, 14850 Ithaca, NY, USA \\ Tel: 1-607-279-8453 E-mail: skm88@cornell.edu \\ Linnet S. Gohole \\ Department of Seed, Crop and Horticultural Sciences, Moi University \\ PO Box 1125, Eldoret, Kenya \\ E-mail: lgohole@africaonline.co.ke \\ Elmada. O. Auma \\ Department of Seed, Crop and Horticultural Sciences, Moi University \\ PO Box 1125, Eldoret, Kenya \\ E-mail: elmadaauma@yahoo.com
}

This research was funded by Samuel Mutiga

\begin{abstract}
Sustainable utilization of the limited land parcels is an important element in resource poor countries whose populations depend on agriculture for sustenance. In East Africa, collard vegetable production has been a venture for many small-scale farmers. Since no approaches are possible in expanding the land resource, improved crop production techniques and management promise better yields. We report a potential and sustainable approach for collard production. We compared the productivity of growing collards in an intercrop with chilli or spring onions, and varying nitrogen levels in each cropping system in terms of land equivalent ratios (LER). Our two - season data show that farmers can obtain higher yield in a unit of land when they intercrop collards with spring onions as indicated by a LER of 1.06, and that growing collards in an intercrop with Chilli leads to a 14\% wastage of land resource compared to growing the crop as a monoculture. Further, we reveal that application of nitrogenous fertilizer might lead to increase in yield but it does not have a statistically significant benefit on the land resource use.

There were no statistically significant relationship between the yield of collards and their heights in all cropping systems, but a non-significant $(\mathrm{r}=-0.29, \mathrm{p}=0.164)$ decline of yield was observed under collard + spring onion intercrop. The number of collard leaves was significantly negatively correlated $(r=-0.456, p=0.0249)$ with yield LER under collard + spring onion intercrop but it did not influence the LER under collard + spring onion intercrop. These findings demonstrate the need for proper resource application, and that collard + spring onion intercrop has a potential to improve collard yield per unit piece of cultivated land without a need for increasing the rate of nitrogenous fertilizer application.
\end{abstract}

Keywords: Land Equivalent Ratio (LER), Collard, Chilli, Spring onion, Sustainability, Land use, Intercrop, Nitrogen fertilizer $(\mathrm{N})$

\section{Introduction}

Collards, Brassica oleraceae var acephala (L.), are globally important leafy vegetables, and mainly grown for subsistence and cash by small-scale farmers and many households at kitchen garden levels especially in the tropics and sub-tropics. In Kenya, women take a lead in both production and marketing activities (Nyambo and Pekke, 1995), with clusters of collard and kale selling kiosks established along major highways and proximal to 
most residential areas (pers. Observ.). Developing nations have relentlessly demonstrated the need for increased food production to feed the burgeoning populations, using limited land resources that cannot be expanded, and thus the urge to adopt better crop production systems (FAO 2009). Research on methods to improved vegetable production, in particular for collards and kales have immense implications on the land resource poor farmers among the East African communities.

Collards "sukumawiki" serve as major dish accompaniment in Kenya, and are mainly served with a stiff porridge, corn meal, known as ugali. There are several collard production constraints including poor soils, diseases and pests, poor production systems, and limited resources, among others (Heifer International 2010). The lack of land and other resources among majority of collard farmers further indicate the underlying need to marshal both technology, and natural resources therein to sustainable achievement of superlative benefits in collard farming. One such option is utilization of the knowledge on soil conditions and cropping systems' relationship in reaping maximum collard yields from a land unit. The intensive cultivation of this crop calls for special production approaches to ensure maximum yield from the limited available land.

Most farmers apply calcium ammonium nitrate (CAN) as a top-dress to improve the yields of leafy vegetables, (Kipkosgei et al., 2003), and collards respond well to N fertilization (Scaife \& Turner, 1985; Scaife \& Bar-Yosef, 1995). Other vegetable production improvement approaches include the application of botanicals, as pesticides, and/or crude intercrop trials as pest control methods (Said and Itulya, 2003).

Although an increase in yield has been reported upon increased $\mathrm{N}$ and synthetic pesticide application, the associated costs can only be met by large-scale growers. Besides, there is also a current public outcry for need for organic farming; with reduced synthetic pesticide use (Birech et al., 2006). Any research on better crop production methods that minimize use of environmental pollutants, and maximize yield under sustainable field conditions would then be a boost to small-holder farmers.

Intercropping and companion cropping have been a common practice in African agriculture, with most cereals and legumes grown as intercrops (Said and Itulya, 2003; Runkulatile et al., 1997; Wortmann, 1993). Although most farmers aim at obtaining yields from different crop species used, reports indicate other positive synergies in most of these cropping systems. Among the benefits of intercropping are: efficiency in land use, as measured by Land Equivalent Ratio (LER) (Kantor, 1999), increased crop health and yield attributable to lack of insect pest preference on the crop, and the associated reduction in cost of production due to less need for synthetic chemical application (Sullivan, 1998). Companion cropping (e.g. cabbages, Brassica oleraceae var capitata (L.), are grown in a mix or in parallel rows with geraniums, Pelargonium spp.) has been associated with similar advantages except that the companion plant may not be necessarily a target crop for the farmer. With the increasing high cost of living in East Africa, farmers may have less preference for companion cropping, but instead they might only practice intercropping with crops that have a positive synergy and can be used for their subsistence and cash needs.

LERs have been used as a measure of crop performance under intercrop methods. However, in most cases, the assessments do not involve the soil - cropping system complex and its effects on crop performance. Such an assessment is beneficial to collard growers since it would be economical for them to use minimal fertilizer application rates and obtain optimal yields for not only collards but other crops that work well within the chosen intercropping system.

Given that the vegetative growth and the yield of collards increase with increase in nitrogen application rate, and that the collard + spring onion intercrop system has been reported to reduce major pests, such as aphids (Mutiga et al., 2010) in this crop, there was need to understand whether the aforementioned benefits had an effect on land resource utilization. We thus carried out a comparison of two intercropping methods (Collard + Chilli and Collard + Spring onion) under differential nitrogen applications based on LER.

The aims of this study were: (1) To compare the gains in terms of land use efficiency for the two intercrop methods herein and (2) to explore the possibility of increasing $\mathrm{N}$ levels in either of the intercrop methods in-order to maximize the yield of collards per unit piece of land.

\section{Materials and methods}

Field studies were carried out in two collard growing seasons, February - May (season 1) and June - August (season 2) of 2006 at Chepkoilel campus $\left(0^{\circ} 34^{\prime} 35^{\prime \prime} \mathrm{N} ; 35^{\circ} 18^{\prime} 13^{\prime \prime} \mathrm{E}, 2154 \mathrm{~m}\right.$ a.s.l.) of Moi University, Eldoret, Kenya. Chepkoilel region has a rainfall range of $1000-1520 \mathrm{~mm}$ per annum, mean temperature range of $9{ }^{\circ} \mathrm{C}$ (night) to $26^{\circ} \mathrm{C}$ (day), soils are underlain by tertiary volcanic rocks (phenolites) and murram, and a prevailing pH range of 4.5-5 (Jaetzold \& Schmidt, 1983). Farmers in this region primarily rely on nitrogenous fertilizers to 
boost collard productivity; with a blanket application rate of approximately 20 g of CAN $(26 \% \mathrm{~N})$ per collard stem.

\subsection{Source of materials and experimental design}

Collard (Georgia cultivar.) and chilli, Capsicum frutescens (L.), (Red cayenne cultivar) seeds were purchased from local seed stores in Eldoret town. Spring onion, Allium cepa (L.), splits were obtained from Eldoret Municipality open-air-market. Both chilli and spring onion seedlings were raised on a nursery bed until they were ready for transplanting. The chilli and spring onion seedlings were transplanted when collard seedlings were 3 -weeks old.

The experimental design consisted of two intercrops, Collard + Chilli; Collards + Spring onion, and a Collard monoculture (sole Collards). Fourteen days after transplanting, when collards had developed good root system, calcium ammonium nitrate $(\mathrm{CAN})$ fertilizer $(26 \% \mathrm{~N})$ was applied as a top-dress at different rates $(20,25,30$ and 35 grams plant ${ }^{-1}$ ).

The experimental layout consisted of 12 treatments replicated three times, with each replicate forming a complete block. Each treatment plot measured $2.8 \mathrm{~m} \times 2.8 \mathrm{~m}$; with a one meter wide path between blocks, and a $50 \mathrm{~cm}$ path between individual plots in a block. Spacing between plants was as follows: $40 \mathrm{~cm}$ intra-row for all plants; $40 \mathrm{~cm}$ inter-row for collard monoculture, and $20 \mathrm{~cm}$ between collard and chilli or spring onion rows. A zigzag conformation of plants was adopted between collard and chilli or spring onion rows, an approach assumed to have had better utilization of field space and other resources. Each plot had a $15 \mathrm{~cm}$ bare belt, where no crop was planted. Collard monoculture plots had a maximum of 49 plants while intercrops had a maximum of 91 plants.

\subsection{Sampling}

Although some farmers begin harvesting of collard leaves when the leaves are still very young, about 5 weeks after transplanting, we chose to compare the fresh leaf weight (yield) based on the maximum initial leaf harvest; while the leaves are still tender and marketable. Thus, data used for production of this manuscript was collected at 7-weeks after transplanting of collards.

A week after application of the $\mathrm{N}$ fertilizer top-dress, three rows of collard plants were selected at random from each treatment plots, and 3 collard plants randomly tagged in each row excluding plants in the guard rows. Data was collected from these plants on leaf fresh weight (yield) ( $t / h a)$, scores for aphid infestation, number of leaves (leaf count per plant) and plant height $(\mathrm{cm})$.

Plant height represented the distance from the base of the plant at soil level to the apex. We counted all visible leaves in each plant. Further, we made observations and approximations of aphid infestation levels on one leaf each on either top, middle or bottom parts of the collard plant. Aphids were scored in a scale of 0 to 6 (where, $0=$ no aphids observed; $1=>20$ aphids/plant, $2=21$ to 50 aphids/plant, $3=51$ to 100 aphids/plant, $4=101$ to 200 aphids/plant, $5=201$ to 400 and $6=>400$ aphids/plant). In order to ease the scoring, photos of leaves with different levels were first taken; aphids counted and were used as guides. Yield of the collards was determined by harvesting all leaves that had attained harvesting maturity (as per our own observations) on the nine plants in each of the plots. The leaves were weighed using a beam balance and the weight expressed in grams for the whole plot, but later converted into t/ha.

\subsection{Data analysis}

Statistical analysis was done using JMP software (JMP, Version 7. SAS Institute Inc., Cary, NC, 1989-2007), and Microsoft Excel version 2003. All data was subjected to analysis of variance (ANOVA) in a linear model with replications nested in a season in testing major effects and their interactions on the response factors. Land Equivalent Ratio (LER) was computed in Ms Excel by dividing the collard yield from each of the cropping systems by that of the monoculture. A t-test was used to compare the LER computed from Collard + Spring onion intercrop with that from Collard + Chilli intercrop. A correlation analysis was done between the LER and plant height, number of leaves per plant and the aphid density observed in each of the treatments.

\section{Results}

Collard + Spring onion intercrops had significantly $\left(\mathrm{t}_{46}=4.68 ; \mathrm{P}<0.001\right)$ higher LER (1.06) compared to Collard + Chilli intercrop (0.86). Growing collards as monoculture would thus require 1.06 times the size of land to obtain the same yield as when under Collard + Spring onion intercrop. On the other hand, if a farmer was to practice Collard + Chilli intercropping, he/she would have to use 1.2 times the size of land in order to obtain the same yield as that in monoculture. 
There were no significant $(\mathrm{P} \leq 0.05)$ differences in LER between the seasons in which the crop was grown (Table 1). Similarly, although increasing the $\mathrm{N}$ dosage generally increased the LER under Collard + Spring onion intercrop, the amount of nitrogen applied did not significantly contribute to the variation in LER in each of the intercrop regimes. Generally, in the Collard + Spring onion intercrop, the two highest $\mathrm{N}$ dosages gave the lowest LER (Table 2).

There were no statistically significant relationship between the yield of collards and their heights in all cropping systems, but a general non-significant $(\mathrm{r}=-0.29, \mathrm{p}=0.164)$ decline in the yield was observed under Collard + Chilli intercrop. We observed a significant negative correlation $(r=-0.456, \mathrm{P}=0.0249)$ between the number of Collard leaves and yield LER under Collard + Chilli intercrop but not under Collard + Spring onion intercrop.

Although we have reported that aphid density led to decline in yield of collards when scouting was done for 20 days at 5 day intervals (Mutiga et al. 2010), our ANOVA does not reveal any significant relationship between aphids and LER in this study.

\section{Discussion}

LER has been used as an estimator for land resource utilization in many agronomic studies (Yadav \& Yadav 2000; Said \& Itulya, 2003). Our data shows that Collard + Spring onion intercrop was better in land resource utilization compared to Collard + Chilli intercrop. Our observation is in concurrent with those by Said \& Itulya (2003) who reported decreased infestation of collards by Plutella xylostella (L.) and increased productivity as measured in LER under bean and bulb onion intercrops. The possible explanations for the observation above are that spring onions had some beneficial effects in the cropping system, which might have included repulsion of insect pests (Mutiga et al., 2010; Said \& Itulya, 2003). The contrasting results from Collard + Chilli onion intercrop might be due to its wide vegetative architecture which might have effectively competed growth resources with the collard crop (Harvey \& Eubanks, 2004).

Our results show that LER was not affected by $\mathrm{N}$ application (Table 2), suggesting that farmers can just produce enough of high quality collards without increasing the fertilizer dosage from the blanket recommendation of $20 \mathrm{~g}$ plant $^{-1}$. In contrast, we have previously reported highest collard yields under Collard + Spring onion intercrop under $30 \mathrm{~g}_{\text {plant }}{ }^{-1} \mathrm{~N}$ rate, but the observed yield did not differ statistically with the one under a $\mathrm{N}$ rate of $35 \mathrm{~g}$ plant $^{-1}$ under the same cropping systems (Mutiga et al., 2010). Since fertilizers are very expensive to the small scale farmers, in terms of resource utilization and sustainability, these findings indicate that the choice of cropping system would be more important than increasing the $\mathrm{N}$ dosage. Ghaley et al. (2005) showed that intercropping spring wheat and field pea gave maximum productivity, with high dry matter and grain yield, without adding $\mathrm{N}$ fertilizer compared to spring wheat monoculture. Since our intercrop did not involve a leguminous crop, which is capable of fixing $\mathrm{N}$, as was the case with Ghaley et al (2005), we speculate that spring onions could have only acted indirectly in improvement of the LER by repelling major insect pests. Furthermore, we reported lower aphid infestation under Collard + Spring onion cropping system compared to Collard + Chilli intercrop and the Collard monoculture, and high aphid infestations on collards were observed on the 35 and 40 but not at 45 days after transplanting of collards (Mutiga et al. 2010). A plausible explanation for the lack of significant influence of aphids on LER at the $7^{\text {th }}$ week after transplanting could be that the insects were dislodged by rainfall. For a resource limited farmer, reduced application of farm input in form of fertilizers, without a compromise on the yield of collard crop would be a great benefit. On the other hand, intercropping chilli with collards gave lower yield compared to the rest of the cropping systems under all nitrogen rates (Mutiga et al., 2010). This could be attributed to the high vegetative nature of chilli that might have successfully competed with Collards for the available growth resources. We speculate that chilli effectively competed for the growth resources with the collards, and this led to thin tall collard plants that had small and low quality leaves hence the low yield and consequently the LER under this intercrop. Furthermore, we observed a significantly negative correlation $(\mathrm{r}=-0.456, \mathrm{p}=0.0249)$ between the number of collard leaves and yield LER under Collard + Chilli intercrop but not under Collard + Spring onion intercrop. Reduced collard leaf quality accompanied with a general low vigor was a characteristic of the Collard + Chilli intercrop (pers. observ.). Growth duration of intercrops, if similar, can lead to competitive resource utilization (Fukai and Trenbath, 1993), implying that the best suited wins over the less competitive crop and hence less yields. Intercropping chilli with collards thus would not be of any benefit in collard productivity, and especially where the land resource is a limiting factor.

The lack of significant difference in LER for the two seasons implies that the intercrop plants were not affected differently by the change in weather conditions and / or their resource utilization did not affect the collard productivity within the experimental lifespan. LER values greater than 1 and increased net incomes have been reported in diverse intercrop systems. For example, Yildirim \& Guvenc (2006) reported that when cabbage, were 
intercropped with lettuce, Lactuca sativa (L.), onions, Allium sp., and beans, Phaseolus Vulgaris (L.), they showed LER greater than 1 under all intercrops as well as increased net returns regardless of the growing season. However, Yildirim \& Guvenc (2006) also reported a negative effect on growth of cabbage when the crop was intercropped with radish, Raphanus sativus (L.).

Agronomic manipulation of crop growth environment and choice of complimentary intercrops to improve productivity is a puzzle agronomists and farmers try to solve in order to reap increased net returns. For ages, fertilizer application has been common, but today, as the study shows, the ability to master the concept of intercropping, complimentary crop choices, to better utilize the limited land resource, is a sustainable way to feed nations whose populations are exploding yet under fixed land units. The intercropping design, combined with aforementioned factors interacting during collard crop growth should lead to an efficient utilization of the limiting resource.

\section{Acknowledgement}

Many thanks to all members of Moi University, School of Agriculture and Biotechnology that helped in both field and lab activities associated with this research.

\section{References}

Birech, R., Freyer, B., \& Macharia, J. (2006). Towards reducing synthetic pesticide imports in favor of locally available botanicals in Kenya. Tropentag 2006 October 11-13 Conference on International Agricultural Research for Development. Bonn, Germany.

FAO. (2009). Global agriculture towards 2050. High Level Expert Forum. Rome, Italy.

Fukai, S., and Trenbath, B. R. (1993). Processes determining intercrop productivity and yields of component crops. Field Crops Research, 34, 247-271.

Ghaley, B. B., Hauggaard-Nielsen, H., Hogh-Jensen, H. \& Jensen, E. S. (2005). Intercropping of wheat and pea as influenced by nitrogen fertilization. Nutrient Cycling in Agrosystems, 73, 201-212.

Ghosh, P.K., Mohanty, M., Bandyopadhyay, K.K., Painuli, D.K., \& Misra, A.K. (2006). Growth, competition, yields advantage and economics in soybean/pigeon pea intercropping system in semi-arid tropics of India: I. Effect of subsoiling. Field Crops Research, 96, 80-89.

Guvenc, I., \& Yildirim, E. (2006). Increasing Productivity with Intercropping Systems in Cabbage Production. Journal of Sustainable Agriculture, 28, 29 - 44.

Harvey, C. T., \& Eubanks, M. D. (2004). Effect of habitat complexity on biological control by the red imported fire ant (Hymenoptera: Formicidae) in Collards. Biological control, 29, 348-358.

Heifer International. (2010). Kenya survey study 2010. Heifer International, 1 World Avenue, Little Rock, AR/USA 72202.

Itulya, F. M., Mwaja, V.N. and Masiunas, J.B. (1997). Collard-cowpea intercrop response to nitrogen fertilization, redroot pigweed density, and Collard harvest frequency. Horticultural Science, 32, 850-853.

Jaetzold, R. \& Schmidt, H. (1983). Farm Management Handbook of Kenya. Natural Conditions and Farm Management Information, Vol. II, Part C. Ministry of Agriculture, Nairobi, Kenya.

JMP $^{\circledR}$, Version 7. SAS Institute Inc., Cary, NC, 1989-2007.

Kantor, S. (1999). Comparing yields with land equivalent ratio (LER). Washington State University, 919 SW Grandy way, Suite 120, Renton, WA, USA.

Mutiga, S. K., Gohole, L.S., \& Auma, E. O. (2010). Effects of integrating companion cropping and nitrogen application on performance and infestation of Collards by Brevicoryne brassicae. Entomologia experimentalis applicata, 134, 234-244.

Nyambo, B. \& Pekke, A. (1995). Brassica Planning Workshop for East and Southern Africa Region, Lilongwe-Malawi. GTZ-IPM Horticulture, Nairobi, Kenya.

Runkulatile, H., Koki, H. Takeshi, H. Takashi, K., \& Tatsuya, I. (1998). Land Equivalent Ratio of GroundnutFinger millet Intercrops as Affected by plant combination ratio and nitrogen and water availability. Plant Production Science, 1, 39-46.

Said, M., \& Itulya, F. M. (2003). Intercropping and nitrogen management effects on diamondback moth damage and yield of Collards in the highlands of Kenya. African Crop Science Journal, 2, 35-42. 
Scaife, M. A., \& Bar-Yosef, B. (1995). Nutrient and Fertilizer Management in Field Grown Vegetables. IPIBulletin 13. International Potash Institute, Basel, Switzerland.

Scaife, M. A., \& Turner, M. K. (1985). Effect of nitrogen top-dressing on Brussels sprout flavor. Tests of Agrochemicals and Cultivars, 106, 172-173.

Sullivan, P. (1998). Intercropping principles and production practices. Appropriate technology transfer for rural areas (ATTRA), Fayetteville, AR. [Online] Available: http://attra.ncat.org/attra-pub/PDF/intercrop.pdf.

Wortmann, C. S., \& Sengooba, T. (1993). The banana-bean intercropping system: Bean genotype times cropping system interactions. Field Crops Research, 31, 19-25.

Yadav, R. S., \& Yadav, O. P. (2000). Differential Competitive Ability and Growth Habit of Pearl Millet and Cluster bean Cultivars in a Mixed Cropping System in the Arid Zone of India. Journal of Agronomy and crop science, $185,67-71$

Table 1. Seasonal effect on land equivalent ratios for collards intercropped with either chilli or spring onions

\begin{tabular}{|l|lll|}
\hline Intercrop & season & LER & SE \\
\hline Chilli + Collards & 1 & 0.82 & $0.03 \mathrm{~A}$ \\
& 2 & 0.91 & $0.03 \mathrm{~A}$ \\
Spring onion + Collards & 1 & 1.04 & $0.04 \mathrm{~A}$ \\
& 2 & 1.09 & $0.06 \mathrm{~A}$ \\
\hline
\end{tabular}

LER whose SE are followed by similar letters in the same intercrop do not differ significantly ( $\mathrm{P} \leq 0.05$, student's pair-wise t-test).

Table 2. Effect of nitrogen application on LER for collards intercropped with ether chilli or spring onions

\begin{tabular}{|l|lll|}
\hline Intercrop & N (g/plant) & LER & SE \\
\hline Spring onion + Collards & 20 & 0.99 & $0.04 \mathrm{~A}$ \\
& 25 & 1.09 & $0.07 \mathrm{~A}$ \\
& 30 & 1.07 & $0.10 \mathrm{~A}$ \\
& 35 & 1.11 & $0.06 \mathrm{~A}$ \\
\hline Chilli + Collards & 20 & 0.91 & $0.03 \mathrm{~A}$ \\
& 25 & 0.90 & $0.03 \mathrm{~A}$ \\
& 30 & 0.75 & $0.04 \mathrm{~A}$ \\
& 35 & 0.89 & $0.06 \mathrm{~A}$ \\
\hline
\end{tabular}

LER whose SE are followed by similar letters in the same intercrop do not differ significantly $(\mathrm{P} \leq 0.05$, Tukey HSD test). 